\title{
Obtaining of powders of tungsten and molybdenum by reduction of their oxides by aluminium in a melt of chloride of alkali metals
}

\author{
V.V. Gostishchev ${ }^{1,2, \dagger}$ I.A. Astapov ${ }^{1,2}$ \\ †v-gostishev@mail.ru \\ ${ }^{1}$ Institute of Materials of Far Eastern Branch of the Russian Academy of Sciences, Tikhookeanskayast., 153, 680042 \\ Khabarovsk, Russia \\ ${ }^{2}$ Pacific National University, Tikhookeanskayast., 136, 680035 Khabarovsk, Russia
}

\begin{abstract}
A assessment of the current state of research in the field of physico-chemical bases production of powders of tungsten and molybdenum are given. It was noted that traditional technology hydrogen reduction of oxides does not fully meet modern requirements. The problem of producing metal powders of tungsten and molybdenum is offered to solve using the new approach: reduction of oxides of metals is necessary to conduct in the environment of melts of salts of alkali metals. The conditions for producing fine powders of molybdenum and tungsten by reduction of oxygen compounds of aluminum in $\mathrm{NaCl}-\mathrm{KCl}$ melts are studied at temperature of 1100-1200K. Thermal analysis showed that the restoration in the melt, with a deficiency of oxygen occurs less intensively than in air, and fits into the range $700-850^{\circ} \mathrm{C}$. Products of restoration showed that monophase powders of molybdenum and tungsten are formed. It was shown that the yield of the powders reaches $96-98 \%$ due to $25 \%$ excess aluminum concentration in the melt. Purity of powders makes $98,5-99 \%$. The microstructure of the powder is presented by the agglomerates, consisting of particles of round shape less than $2 \mu \mathrm{m}$. It is shown that under equal conditions of synthesis powders of molybdenum have a greater value of specific surface area $\left(45,3 \cdot 10^{5} \mathrm{~m}^{-1}\right)$ than tungsten $\left(32,4 \cdot 10^{5} \mathrm{~m}^{-1}\right)$. It is shown that with increasing concentrations of the reactants in the melt in 4 times, the fraction of particles finer fractions powders increases and as a result, the specific surface area becomes more in 2 times.
\end{abstract}

Keywords: molybdenum, tungsten, powders, ionic melts, granulometry.

\section{Получение порошков молибдена и вольфрама восстановлением их оксидов алюминием в расплаве хлоридов щелочных металлов}

\author{
Гостищев В.В. ${ }^{1,2, \dagger}$, Астапов И.А. ${ }^{1,2}$ \\ †v-gostishev@mail.ru
}

\begin{abstract}
${ }^{1}$ Институт Материаловедения ХНЦ ДВО РАН, ул. Тихоокеанская 153, 680042 Хабаровск, Россия ${ }^{2}$ ФГБОУ ВПО «Тихоокеанский государственный университет», ул. Тихоокеанская 136, 680035 Хабаровск, Россия
\end{abstract}

Дана краткая оценка современного состояния исследований в области разработки физико-химических основ получения порошков вольфрама и молибдена. Отмечено, что традиционная технология водородного восстановления оксидов не в полной мере отвечает современным требованиям. Проблему получения металлических порошков вольфрама и молибдена предложено решать с использованием нового подхода: восстановление оксидов металлов вести в среде расплавов солей щелочных металлов. Изучены условия получения тонкодисперсных порошков молибдена и вольфрама путем восстановления их кислородных соединений алюминием в расплавах $\mathrm{NaCl}$ - KCl при температуре $1100-1200 \mathrm{~K}$. Термический анализ показал, что восстановление в расплавах, при недостатке кислорода, протекает менее интенсивно, чем на воздухе и укладывается в интервал $700-850^{\circ} \mathrm{C}$. Методами рентгенофазового и элементного анализов продукты восстановления идентифицированы как однофазные порошки молибдена и вольфрама. Показано, что выход порошков достигает 96 - 98 мас. \% за счет 25 \% избытка концентрации алюминия в расплаве. Чистота порошков составляет 98,5 - 99 \%. Микроструктура порошков представлена агломератами, состоящими из частиц округлой формы размером менее 2 мкм. Показано, что в равных условиях синтеза порошки молибдена имеют большую удельную поверхность $\left(45,3 \cdot 10^{5} \mathrm{M}^{-1}\right)$, чем вольфрам $\left(32,4 \cdot 10^{5} \mathrm{M}^{-1}\right)$. Показано, что при увеличении концентрации реагентов в расплаве в 4 раза, доля частиц мелких фракций порошков растет и, как следствие, удельная поверхность становится больше в 2 раза.

Ключевые слова: молибден, вольфрам, порошки, ионные расплавы, гранулометрия. 


\section{1. Введение}

Одним из приоритетных направлений современного материаловедения является разработка научных и технологических основ получения металлических порошков - основного сырья порошковой металлургии. Высокодисперсные порошки металлического вольфрама и молибдена представляют интерес для изготовления изделий новой техники, в том числе приборостроения, радиоэлектроники и других отраслях.

Для получения дисперсных порошков предложены технологии, основанные на таких методах как механическое измельчение в мельницах, распыление расплавленного металла, испарение исходных веществ и их конденсация в вакууме, среде разряженных газов, плазменной струе, восстановление в твердой и жидкой фазе, электроосаждение[1-8]. Наибольшее распространение в отечественной практике получил метод химического восстановления оксидов вольфрама и молибдена водородом при 900-1200 ${ }^{\circ} \mathrm{C}$. Метод обеспечивает получение порошков, как правило, с широким диапазоном распределения частиц по размерам. Регулированием режимов восстановления (температуры, времени выдержки в высокотемпературной зоне) удается получать материалы с весьма узкой функцией распределения размера частиц. Вместе стем, получение высокодисперсных металлических порошков строго определенного гранулометрического состава остается проблематичным. Возможности решения проблемы в определенной мере могут быть расширены в результате применения новых методов получения порошков, в частности основанных на проведении восстановительных реакций в среде ионных расплавов. Опыт применения ионных расплавов в качестве среды проведения неорганических реакций показывает, что в этих средах проходят реакции металлотермического восстановления оксидов металлов. Это позволяет получать высокодисперсные порошки металлов с высокой скоростью[9]. При этом дисперсноть порошков зависит от условий их получения: состава расплава, температуры,величины удельной поверхности восстановителя и других факторов. Так, например установлено, что в относительно разбавленном растворе $\left(\mathrm{WO}_{3}: \mathrm{NaCl}=1: 20\right)$ формируются порошки со средней величиной удельной поверхности равной $16,8 \cdot 10^{5} \mathrm{M}^{-1}$. В то время как с повышением концентрации реагирующих веществ в объёме расплава удельная поверхность получаемых порошков растет.

Настоящая работа посвящена получению тонкодисперсных порошков молибдена и вольфрама восстановлением их кислородных соединений алюминием в расплаве хлоридов щелочных металлов в условиях переменных концентраций реагирующих компонентов.

\section{2. Материал и методика исследования}

В качестве исходных компонентов реакционных смесей использовались, (чистота, в мас.\%): $\mathrm{Na}_{2} \mathrm{MoO}_{4}-99,0$; $\mathrm{Na}_{2} \mathrm{WO}_{4}$ - 98,9; порошок алюминия Al-99,5 (50 мкм); $\mathrm{NaCl}$ и $\mathrm{KCl}-$ х.ч.
Для определения элементного состава использовался рентгенофлуоресцентный анализатор «Спектроскан Макс-GV». Исследование фазового состава выполнялось на дифрактометре «ДРОН-7» $\left(\mathrm{Cu}_{\mathrm{Ka}}\right.$-излучение). Термический анализ осуществлялся на установке «DerivatographQ-1000». Гранулометрические параметры порошков определялся на приборе «Analysette 22». Микроструктура исследовалась с помощью электронного микроскопа «Hitachi SU-70».

\section{3. Результаты и обсуждение}

Процесс получения порошков состоит из высокотемпературного растворения исходных соединений вольфрама и молибдена $\left(\mathrm{Na}_{2} \mathrm{WO}_{4}, \mathrm{Na}_{2} \mathrm{MoO}_{4}\right)$ в расплаве $\mathrm{NaCl}-\mathrm{KCl}$ и их восстановления алюминием в расплаве. Перемешивание расплава ускоряет формирование агломерированных частиц вольфрама и молибдена. Продукты восстановления отделяют от расплава декантацией, отмывают от остатков солей подкисленной $\mathrm{HCl}$ водой $(1: 15)$ при нагревании до $70-80^{\circ} \mathrm{C}$, в результате чего весь процесс получения целевого продукта занимает не более 1,5-2 ч. Реакции восстановления молибдена и вольфрама с определенной долей приближения описываются уравнениями:

$$
\begin{aligned}
& \mathrm{Na}_{2} \mathrm{MoO}_{4}+2 \mathrm{Al}=\mathrm{Mo}+2 \mathrm{NaAlO}_{2} \\
& \mathrm{Na}_{2} \mathrm{WO}_{4}+2 \mathrm{Al}=\mathrm{W}+2 \mathrm{NaAlO}_{2}
\end{aligned}
$$

Термодинамическая оценка показывает, что вероятность прохождения этих реакций довольно высока (табл.1). Восстановление сопровождается значительной убылью величины изобарного потенциала $(\Delta G)$ и протекает при весьма больших значениях константы равновесия $\left(\lg K_{p}\right)$. Процесс протекает с высокой скоростью до полного исчерпания исходных веществ, что характерно для необратимых реакций.

Алюминотермическое восстановление оксидов молибдена и вольфрама в среде хлоридов охарактеризовано методом дифференциального термического анализа.

Таблица 1. Температурные зависимости термодинамических параметров реакций восстановления

Table 1. Temperature dependence of the thermodynamic parameters of the reduction reactions

\begin{tabular}{|c|c|c|c|c|}
\hline $\begin{array}{c}\text { Reaction № } \\
\text { Реакция № }\end{array}$ & $T, \mathrm{~K}$ & $\begin{array}{c}\Delta H, \mathrm{~kJ} / \mathrm{mol} \\
\Delta H, \text { кДж/моль }\end{array}$ & $\begin{array}{c}\Delta G, \mathrm{~kJ} / \mathrm{mol} \\
\Delta G, \text { кДж/моль }\end{array}$ & $\lg K_{p}$ \\
\hline \multirow{3}{*}{1} & 898 & -956 & -596 & 34 \\
\cline { 2 - 5 } & 1098 & -1051 & -504 & 32 \\
\cline { 2 - 5 } & 1273 & -1094 & -414 & 17 \\
\hline \multirow{3}{*}{2} & 898 & -938 & -875 & 51 \\
\cline { 2 - 5 } & 1098 & -1012 & -856 & 44 \\
\cline { 2 - 5 } & 1273 & -1018 & -832 & 34 \\
\hline
\end{tabular}


Определены температурные интервалы превращений в системах $\mathrm{MoO}_{3}-\mathrm{Al}-\mathrm{NaCl}, \mathrm{WO}_{3}-\mathrm{Al}-\mathrm{NaCl}$. Анализ показал, что взаимодействие оксидов молибдена и вольфрама с алюминием в среде, например, хлорида натрия при недостатке кислорода протекает менее интенсивно, чем на воздухе и укладывается в интервалы $700-800^{\circ} \mathrm{C}\left(\mathrm{MoO}_{3}\right)$ и $760-850^{\circ} \mathrm{C}\left(\mathrm{WO}_{3}\right)$ - рис. 1. Результаты термического анализа согласуются с известными данными для молибдатных и вольфраматных систем [10,11].

В ходе экспериментального определения параметров получения порошков молибдена и вольфрама установлено, что восстановление исходных соединений при стехиометрическом соотношении реагентов обеспечивает выход 82 мас.\% порошка молибдена и 87 мас.\% порошка вольфрама. Выход порошков повышается в результате введения в расплав избытка алюминия относительно расчетного и достигает 96 мас.\% (Мо) и 98 мас.\% $(\mathrm{W})$ при использовании 25 \% избытка восстановителя (рис.2). Наблюдается тенденция к росту величины выхода порошков в результате изменения соотношения исходных компонентов реакционной среды при сохранении прочих условий(рис.3).

Следует заметить, что формирование твердой дисперсной фазы в условиях ионных расплавов связано со сложным характером течения восстановительного процесса, обусловленного их строением. С позиции концепции квазикристаллического строения ионных расплавов их рассматривают как аналоги твердых кристаллических веществ. Однако в ионном расплаве сохраняется лишь ближний порядок во взаимном расположении частиц, тогда как дальний порядок при плавлении разрушается. Структурными составляющими расплавов являются: простые ионы разноименного заряда, недиссоциированные молекулы, полимеризованные молекулы, комплексные ионы различного знака, свободные объемы[12]. Такая сложная картина строения расплавов затрудняет однозначную интерпретацию механизма формирования твердой фазы. Вместе с тем, округлая форма частиц полученного вольфрама,установленная при экспериментальном определении структуры (рис.4), косвенно указывает на преобладающий вклад жидкоподобной коалесценции в механизм их формирования[13].

Присутствие в системе жидких и твердых частиц свидетельствует о характере коалесценции- слияние может происходить при столкновении жидких и твердых частиц. При этом центрами кристаллизации могут служить частицы восстановителя- алюминиевого порошка. Известно, что при увеличении количества центров кристаллизации в единице объема происходит уменьшение среднего размера частиц порошка. С учетом этого обстоятельства можно ожидать влияния взаимного соотношения реагентов в системе на дисперсность получаемых металлических порошков. С целью выявления такого влияния порошки металлов получали в расплавах с переменным отношением компонентов, например, $\mathrm{Na}_{2} \mathrm{WO}_{4}: \mathrm{NaCl}-\mathrm{KCl}=1: 20 ; 1: 15 ; 1: 10 ; 1: 5$. Дозировку алюминия выдерживали равной стехиометрическому расчету. Таким образом, в условиях переменных концентраций реагирующих в расплаве веществ получены порошки молибдена и вольфрама. Методом рентгенофа-
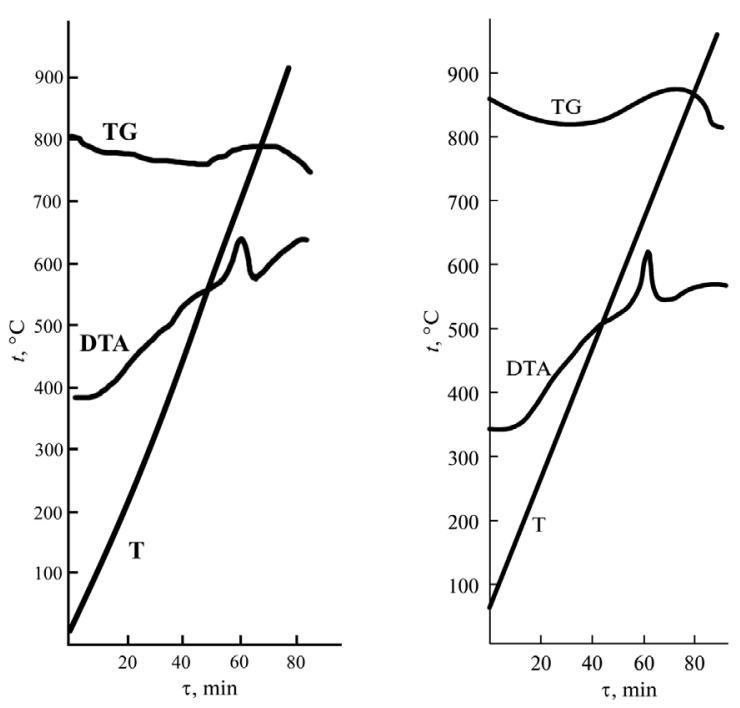

Рис. 1. Термограммы взаимодействия оксида вольфрама и молибденас алюминием: a - $\mathrm{WO}_{3}-\mathrm{Al}-\mathrm{NaCl}$, b - $\mathrm{MoO}_{3}-\mathrm{Al}-\mathrm{NaCl}$.

Fig. 1. Thermograms interaction of tungsten oxide and molybdenum with aluminum:a - $\mathrm{WO}_{3}-\mathrm{Al}-\mathrm{NaCl}, \mathrm{b}-\mathrm{MoO}_{3}-\mathrm{Al}-\mathrm{NaCl}$.

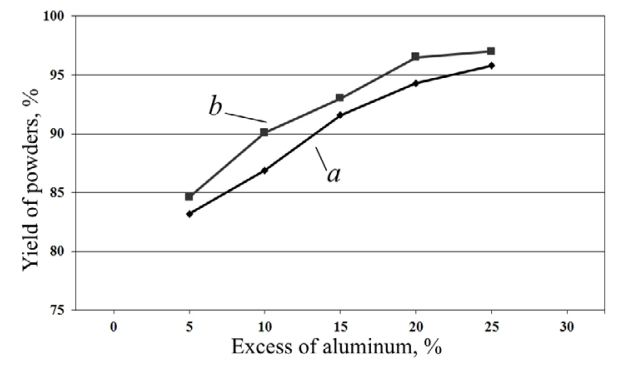

Рис. 2. Зависимость выхода порошков металлов от избытка алюминия в расплаве $\mathrm{NaCl}-\mathrm{KCl}:$ а- молибден; b-вольфрам.

Fig. 2. Dependence of yield metal powders from excess aluminum in the melt NaCl-KCl: a - molybdenum; b - tungsten.

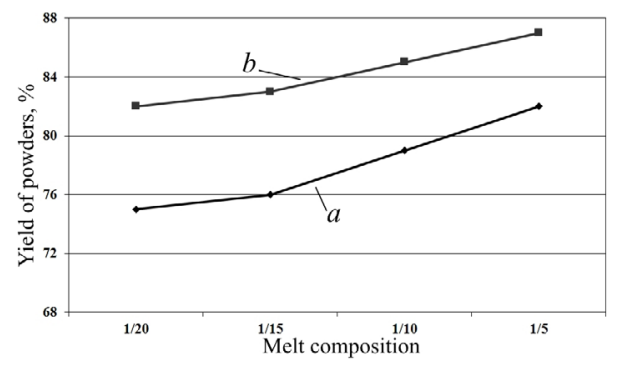

Рис. 3. Зависимость выхода порошков от соотношения $\mathrm{Na}_{2} \mathrm{MoO}_{4}$ (a) и $\mathrm{Na}_{2} \mathrm{WO}_{4}$ (b) к солевой смеси $\mathrm{NaCl}-\mathrm{KCl}$, г.

Fig. 3. Dependence of the ratio of the powders $\mathrm{Na}_{2} \mathrm{MoO}_{4}$ (a) and $\mathrm{Na}_{2} \mathrm{WO}_{4}$ (b) a mixture of salt $\mathrm{NaCl}-\mathrm{KCl}, \mathrm{g}$.

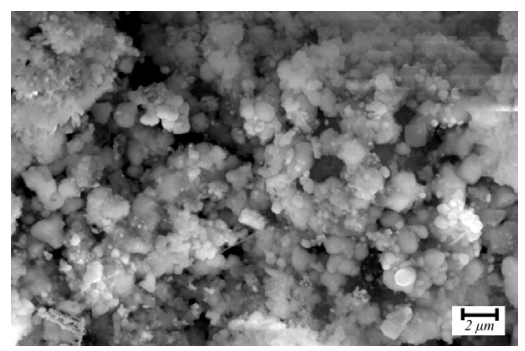

Рис. 4. Микроструктура порошка вольфрама.

Fig. 4. The microstructure of tungsten powder. 
зового анализа порошки идентифицированы как молибден и вольфрам в металлической фазе (рис. 5).

По данным элементного анализа содержание примесных элементов в полученных порошках не превышает 1-1,5\%. Порошки имеют следующий состав, мас.\%: Мо-98,5; Fe-0,3; $\mathrm{Cu}-0,3 ;$ неметаллические примеси-0,4. $\mathrm{W}-98,8 ; \mathrm{Fe}-0,2 ; \mathrm{Cu}-0,3 ;$ неметаллические примеси-0,4.

Экспериментально с использованием дифракционного анализатора установлен гранулометрический состав порошков. При обработке данных дифракционного анализа определена удельная поверхность. Результаты сравнительного гранулометрического анализа полученных порошков приведены в таблице 2, показаны на рисунке 6.

Из данных следует, что концентрации реагирующих компонентов оказывают влияние на дисперсность получаемых порошков. Так увеличение концентрации реагентов за счет сокращения объёма реакционной среды ( $\mathrm{NaCl}-\mathrm{KCl})$ в четыре раза приводит к тому, что число частиц мелких фракций порошков растет и как следствие удельная поверхность становится больше в два раза.

Предлагаемый метод позволяет получать дисперсные порошки, в отличие от многостадийных методов, по упрощенной схеме $[14,15]$.

\section{4. Заключение}

Обобщая результаты проведенных исследований можно заключить, что восстановление кислородных соединений молибдена и вольфрама алюминием в среде расплава $\mathrm{NaCl}-\mathrm{KCl}$ при температуре 1100-1200 К приводит к формированию тонкодисперсных металлических порошков. Экспериментально найдено, что выход порошков достигает максимума (96-98\%) за счет 25\% избытка алюминия относительно расчетного. Выявлено влияние

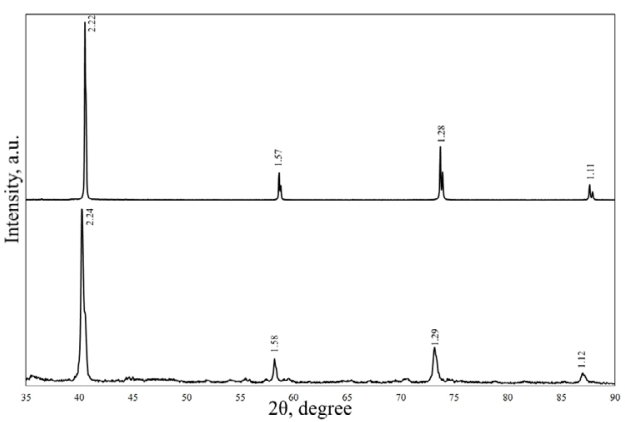

Рис. 5. Дифрактограммаобразцов: 1 - Mo, 2 - W. Fig. 5. XRD-pattern of the sample: $1-\mathrm{Mo}, 2-\mathrm{W}$.

Таблица 2. Результаты сравнительного гранулометрического анализа порошков молибдена и вольфрама Table 2. Results of comparative particle size analysis of tungsten and molybdenum powders

\begin{tabular}{|c|c|c|c|c|c|c|}
\hline $\begin{array}{c}\text { Powder } \\
\text { Наименование }\end{array}$ & \multicolumn{2}{|c|}{$\begin{array}{l}\text { Meltcomposition } \\
\text { Состав расплава }\end{array}$} & $\begin{array}{c}\text { Mean } \\
\text { diameter, um } \\
\text { Средний }\end{array}$ & $\begin{array}{c}\text { Modal } \\
\text { diameter, um } \\
\text { Модальный }\end{array}$ & $\begin{array}{c}\text { Maximum } \\
\text { diameter, um } \\
\text { Максимальный }\end{array}$ & $\begin{array}{c}\text { Specific surface } \\
\text { area } \cdot 10^{5} \mathrm{~m}^{-1} \\
\text { Удельная }\end{array}$ \\
\hline \multirow{3}{*}{$\begin{array}{l}\text { Molybdenum } \\
\text { Молибден }\end{array}$} & \multirow{3}{*}{$\frac{\mathrm{Na}_{2} \mathrm{MoO}_{4}}{(\mathrm{NaCl}-\mathrm{KCl})}$} & $1 / 20$ & 6,6 & 7,2 & 34,8 & 21,3 \\
\hline & & $1 / 10$ & 2,6 & 2,5 & 6,4 & 39,2 \\
\hline & & $1 / 5$ & 2,3 & 2,0 & 5,3 & 45,3 \\
\hline \multirow{3}{*}{$\begin{array}{l}\text { Tungsten } \\
\text { Вольфрам }\end{array}$} & \multirow{3}{*}{$\frac{\mathrm{Na}_{2} \mathrm{WO}_{4}}{(\mathrm{NaCl}-\mathrm{KCl})}$} & $1 / 20$ & 11,8 & 16,9 & 46,9 & 14,4 \\
\hline & & $1 / 10$ & 7,1 & 9,3 & 37,4 & 21,3 \\
\hline & & $1 / 5$ & 2,9 & 3,4 & 8,2 & 32,4 \\
\hline
\end{tabular}
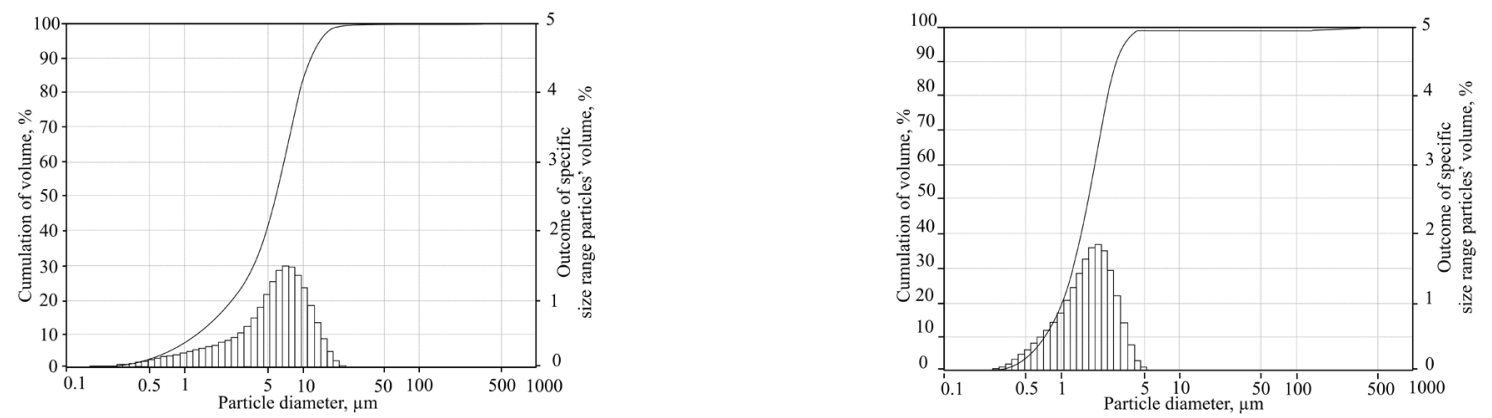

Рис. 6. Гистограммы порошков молибдена, полученных из расплавов с переменным соотношением компонентов $\mathrm{Na}_{2} \mathrm{MoO}_{4}: \mathrm{NaCl}-\mathrm{KCl}: \mathrm{a}-1: 20 ; \mathrm{b}-1: 5$.

Fig. 6. Histograms molybdenum powders obtained from the melt with a variable ratio of the components $\mathrm{Na}_{2} \mathrm{MoO}$ : $\mathrm{NaCl}^{-\mathrm{KCl}} \mathrm{a}-1: 20$; $\mathrm{b}-1: 5$ 
концентрации реагирующих компонентов на дисперсность получаемых порошков. Показано, что увеличение концентрации реагентов в 4 раза за счет изменения соотношения $\mathrm{Na}_{2} \mathrm{MoO}_{4}$ : NaCl-KCloт 1:20 до 1:5 приводит к тому, что число частиц мелких фракций порошков растет и, как следствие, удельная поверхность становится больше в 2 раза.

\section{Литература/References}

1. C.W. Won, H.H. Nersisyan. Curr. Opin. Solid State Mater. Sci. 14, 53-68 (2010).

2. T. Ryu, H.Y. Sohn et al. Int. J. Refract. Met. Hard Mater. 27, 149-154 (2009).

3. H.H. Nersisyan, H.I. Won et al. Powder Technol. 189, 422-425 (2009).

4. R. Ricceri, P. Matteazzi. J. Alloys Compd. 358, 71-75 (2003).

5. T. Wang, H. Gao.Electrochem. Commun. 13, 1492-1495 (2011).

6. P.K. Sahoo, S. Srinivas et al. J. Mater. Res. 26, 652-657 (2011).

7. J.C. Jung, S.G. Ko et al. J. Mater. Res. 11,1825-1830 (1996)

8. C.W.Won, J.C. Jung et al. Mater. Res. Bull. 34, 2239-2245 (1999).
9. V.V. Gostishchev, I.A. Astapov et al. Materials science, 11, 54-57 (2010) (in Russian) [В.В. Гостищев, И.А. Астаповидр. Материаловедение, 11, 54-57 (2010)].

10. V.A. Podergin Metallotermicheskie sistemy. Moscow, Metallurgy, 1992, 271 p.(inRussian) [В.А. Подергин Металлотермические системы. М.: Металлургия, 1992. - 271 c.]

11. M.V. Mohosoev, F.P. Alekseev, V.I. Lucyk Diagrammy sostoyaniya molibdatnyh i volframatnyh sistem. Novosibirsk, Nauka, 1978. - 320 p. (inRussian) [M.B. Мохосоев, Ф.П. Алексеев, В.И. Луцык Диаграммы состояния молибдатных и вольфраматных систем. Новосибирск, Наука, 1978. - 320 с.]

12. Yu.K. Delimarsky. Chemistry of ionic melts. Kiev, Naukova Dumka. (1980) 328 p. (in Russian) [Ю.К. Делимарский. Химия ионных расплавов. Киев, Наукова Думка. 1980. 328 с.]

13. R.U. Kalamazov, Yu.V. Tsvetkov. Fine powders of tungsten and molybdenum. Moscow, Metallurgy. (1988) 192 p. (in Russian) [Р.У. Калмазов, Ю.В. Цветков. Высокодисперсные порошки вольфрама и молибдена. Москва, Металлургия. 1988. 192 с.]

14. Leo V. M. Antony, Ramana G. Reddy. JOM. 55, 1418(2003).

15. P.K. Sahoo, S.S.K. Kamal et al. Int. J. Refract. Met. Hard Mater. 27, 784-791 (2009). 